\title{
Randomized Equivalence Trial of Intensive and Semiannual Applications of Fluoride Varnish in the Primary Dentition
}

\author{
P. Weinstein $^{\mathrm{a}} \quad$ C. Spiekerman ${ }^{\mathrm{a}} \quad$ P. Milgrom ${ }^{\mathrm{b}}$

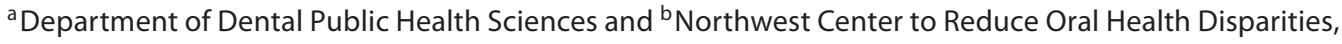 \\ University of Washington, Seattle, Wash., USA
}

\section{Key Words}

Children · Early childhood caries • Fluoride varnish •

Oral health $\cdot$ Randomized clinical trial

\begin{abstract}
For children in the primary dentition with high caries prevalence the standard semiannual application of fluoride varnish may not be successful in preventing tooth decay. Oftentimes this population is mobile and does not receive consistent preventive care. This trial tested whether an intensive fluoride 5\% sodium varnish regimen (three applications/2 weeks) applied annually has an equivalent effect on caries progression in the primary dentition compared to single applications applied semiannually. This study was a randomized clinical trial with two treatment groups. All participants ( $n=600$; mean age $\pm S D=55.3 \pm 4.6$ months) received three varnish applications (active varnish or placebo) at semiannual visits over 3 years. Once per year the intensivetreatment group received one set of three active treatments and three placebo treatments 6 months later, each time within 2 weeks. The standard group received one active and two placebo treatments every 6 months. Children were assessed clinically at baseline and 12,24 and 36 months after the initiation of the study. The mean (SD) numbers of newly
\end{abstract}

decayed primary tooth surfaces observed over 3 years were 9.8 (8.6) and 7.4 (7.7) in the intensive and standard groups, respectively. The adjusted rate ratio was $1.13(95 \% \mathrm{Cl}=0.94-$ $1.37, p=0.20$ ). In conclusion, the trial failed to demonstrate clear evidence of a difference in efficacy. However, differences of up to $36 \%$ greater rates of caries in the intensive group could not be ruled out, thus equivalence of the treatments cannot be concluded. Copyright $\odot 2009$ S. Karger AG, Basel

For children in the primary dentition with high caries prevalence the standard semiannual application of fluoride varnish may not be as successful in preventing new tooth decay as the same treatment in low- and moderaterisk populations [Murray et al., 1977; Grodzka et al., 1982]. At the same time, the evidence for increasing the frequency of varnish treatments is mixed [Axelsson et al., 1987; Seppä and Tolonen, 1990].

Previously, studies have evaluated the frequency of varnish applications in similar high-caries rate populations in the permanent dentition. In the first, 160 11-yearolds were randomly assigned to receive either $5 \%$ sodium fluoride varnish in the comparison group every 6 months over 3 years or the same varnish 3 times during a single

\section{KARGER}

() 2009 S. Karger AG, Basel

Fax +41613061234 E-Mail karger@karger.ch www.karger.com www.karger.com/cre
Dr. Peter Milgrom

University of Washington

Box 357475

Seattle, WA 98195-7475 (USA)

Tel. +1 206685 4183, Fax +1 206685 4258, E-Mail dfrc@u.washington.edu 
week, once per year in the test group [Petersson et al., 1991]. Decayed surfaces increased in the twice-per-year comparison group and decreased in the test group. A later study compared a single annual application of the same fluoride varnish with three applications within 1 week, once per year, in 11-year-olds [Sköld et al., 1994]. Subjects were not randomly assigned but were followed for 4 years clinically and radiographically. Results suggest significantly less caries progression for the three-application condition for all measures (DMFS, DMFS proximal, sum of scores over 8 surfaces of first molars).

In a more recent controlled trial of fluoride varnish treatments in US Latino and Chinese preschoolers, children were randomly assigned to either once or twice annual treatment or to a no-treatment control [Weintraub et al., 2006]. The study reported a $62.5 \%$ reduction in new tooth decay for twice yearly applications relative to the untreated controls. Only caries-free children were entered into the study. Nevertheless the validity of these findings is suspect because they do not apply to children at high risk and, as a result of dropouts and protocol violations, only $1 \%$ of the test children actually received the full treatment over 2 years.

Two additional studies have recently been published supporting the effectiveness of fluoride varnish in the primary dentition. Both studies had limitations but nevertheless are useful. The first [Lawrence et al., 2008] used a community-randomized, no treatment (no varnish)controlled design in 20 First Nation communities in Northwest Ontario, Canada and neighboring city, nonAboriginal childcare or preschool organizations. Communities were assigned to either fluoride varnish applied in the community setting once every 4 months or no treatment. Children were 6 months to 5 years of age at enrollment $(14 \%<1$ year old, $25 \% 1$ year old). The study reported an $18 \%$ reduction when Aboriginal communities with and without treatment were compared and a $24 \%$ reduction when all children were included. The study reported a relative risk of new dfs of $1.96(95 \% \mathrm{CI}=$ 1.08-3.56) for the control compared to the treatment group.

The second study [Holve, 2008] was a one-group observational study in which American Indian preschoolers received fluoride application at the 9-, 12-, 15-, 18-, 24-, and 30-month well-child visits and the results were compared to a 'historical control' of non-study preschool children from the same community who had dental assessments at an age comparable to the study children (mean 52.8 months). The study concluded that children who received four or more fluoride varnish treatments during the study period had $15.4 \mathrm{dmfs}$ (95\% CI 10.8-20.4) versus $23.6 \mathrm{dmfs}$ (95\% CI 19.5-25.8) for the comparison children, a $35 \%$ reduction in decayed surfaces. Children who received one, two, or three treatments during the study period (21 months) showed no significant difference in $\mathrm{dmfs}$ from the comparison children.

Parents of children from low-income families in the USA encounter numerous cultural or occupational obstacles in presenting their children for the completion of a lengthy preventive regimen, such as twice or more per year [Ensor and Cooper, 2004]. An intensive reapplication regimen, especially if necessary only once per year, presents a public health advantage over twice and 3 times yearly applications. Such treatments might be especially appropriate in institutional settings such as Head Start, WIC, and licensed day care centers [Milgrom et al., 2008].

In a pilot study in the primary dentition, we evaluated the effect of different dosing regimens of fluoride varnish on the progression of caries in 1563 - to 5-year-old children from low-income families in the Yakima Valley in Washington State [Weinstein et al., 2001]. Children were randomly assigned to one of three conditions: one fluoride varnish application semiannually; three fluoride varnish applications within 2 weeks once a year, and three fluoride varnish applications within 2 weeks twice a year. Although the differences were not significant at 1 year, the data suggested that the massive application, either once a year or semiannually, may have an equal or greater effect on tooth decay than the standard semiannual approach.

The hypothesis tested in this trial is that an intensive fluoride varnish regimen (three applications within 2 weeks) applied annually has an equivalent effect on tooth decay progression compared to the standard single applications applied semiannually.

\section{Subjects and Methods}

\section{Design}

The experimental design of this study was a randomized controlled clinical trial with two treatment groups. All participants received three varnish applications (either active varnish or placebo) at each semiannual visit. Once per year the intensive-treatment group received one set of three active treatments and three placebo treatments 6 months later. The standard group received one active and two placebo treatments every 6 months. The blocks of three active/placebo applications were performed within 2week time periods. Children were examined at baseline, 12, 24 and 36 months after the initiation of the study. 


\section{Subjects}

The study population consisted of Hispanic children 3 to 4 years of age living in Yakima County, in central Washington State, USA. The inclusion criteria were: (1) 36-71 months of age; (2) primary caretaker did not anticipate moving out of Yakima county within 36 months; (3) no history of changing residence twice or more within the last 12 months, and (4) at least one sound primary tooth surface present. The only exclusion criterion was for children who were developmentally unable to participate in study.

In the fall of 2003 and 2004, families were informed about the study via parent meetings with the local study coordinator, flyers that were sent home with children, local public radio announcements, and by personal contact with Head Start workers. The Institutional Review Board of the University of Washington approved the study and informed consent of parents was obtained. Consent was primarily in Spanish.

Six hundred children were recruited and enrolled from two non-migrant Head Start programs for Hispanic children in the Yakima Valley: (1) EPIC, with 98 and (2) Washington State Migrant Council (WSMC), with 503 children. Enrollment was increased by $20 \%$ over the original target of 500 children to overcome possible attrition.

\section{Assignment to Treatments}

Children were randomly assigned to one of the two treatment groups by the project statistician (C.S.) using computer-generated randomization lists. The stratification factors were Head Start center (2), enrollment year (2), and previous caries experience (dmfs $0-7$ vs. 8 or more) as determined from a baseline oral examination. Randomization was performed in balanced blocks of 30 within each stratum to ensure roughly equal-sized treatment groups throughout the recruitment period.

\section{Treatments}

The active treatment was a 5\% sodium fluoride varnish (Cavity Shield; Omni Oral Pharmaceuticals, West Palm Beach, Fla., USA). The manufacturer made available a control varnish identical to the active varnish except that it did not contain fluoride. The varnish/placebo was prepared in bulk by the manufacturer each year and packaged by the University of Washington Medical Center Investigational Drug Services in prelabeled 0.3-ml tubes that were identical except for the subject identification numbers printed on the labels.

Varnish was placed on all of the tooth surfaces by trained project staff, who were associated with the Yakima Valley Farm Workers Clinic and supervised by the research team. Each child had his or her teeth cleaned with a toothbrush, dried with cotton gauze, and then coated with the varnish using a disposable brush. After $2 \mathrm{~min}$, surfaces not covered with varnish were redried and recoated - an event occurring in less than $10 \%$ of the applications. Finally, the children were given a cup of water to swish (and drink) to accelerate the setting of the varnish. The after-care instructions given to the Head Start teacher and to the mother were to not give the child anything to eat for $1 \mathrm{~h}$ after the application and to not brush the child's teeth until the following morning.

\section{Endpoint: Caries Incidence}

The primary endpoint is incidence of cavitated carious lesions in the primary teeth. World Health Organization criteria [WHO,
1997] were used to specify cavitation. Dental exams were performed on site in the Head Start locations in portable dental chairs; examiners used head-mounted dental lights. The detection of caries was done using visual/tactile examination [Ismail et al., 1992; Drury et al., 1999]. Study coordinators frequently traveled to schools, centers, and dental offices to secure follow-up examinations.

Annual training and calibration sessions were held prior to each data collection phase (baseline, and 12, 24, and 36 months). Examiners practiced first by viewing slides and then by examining children. Discussion of agreement/disagreement followed each examination. A calibration exercise provided assessment of each examiner's agreement with the 'gold standard'. Interexaminer reliability $(\mathrm{ICC}=0.95)$ and intraexaminer reliabilities on 4 examiners (ICC range 0.82-0.98) were assessed based on 249 examinations on 116 children. ICCs were calculated on dmfs (patient-level) scores.

The caries outcomes reported in this article all refer to the numbers of surfaces with evidence of any caries experience. A surface was determined to present evidence of caries experience if the examiner indicated that the surface was decayed, restored, or missing due to caries. A surface was considered to have experienced new decay between two exams if it was determined to be free of caries experience at the first exam and determined to present evidence of caries experience at the subsequent exam. To avoid overstating the caries experience [Broadbent and Thomson, 2005], if a tooth was observed to be missing due to caries or restored with a crown, then this tooth contributed a total of 3 surfaces to our measure. If a tooth had 3 or more surfaces showing evidence of caries at one exam and then was found to be missing or crowned at a later exam, then this tooth was counted to have experienced one surface of new decay in the interim. Examiners were blinded to treatment assignments.

Power Calculations and Analysis Plan

The primary goal of this study was to evaluate the hypothesis of equivalence of the two treatment groups in terms of tooth decay progression. Toward this goal we estimated the ratio of the rates of tooth decay progression between the two treatment groups. At study outset it was decided that equivalence would be declared if the $95 \%$ CI for the rate ratios was found to be within the interval 0.8-1.2. The trial was designed to have $90 \%$ power to observe this endpoint if indeed the treatments were equivalent. Parameter estimates, derived from a pilot study on a similar population, assumed caries incidence in the standard application group to be 90 events per 1,000 tooth surfaces per year. Univariate analyses compared the rates of newly decayed surfaces between the study conditions, which included treatment cohort, enrollment cohort, Head Start center, gender of child, child's age at baseline, and child's caries status at baseline. A Poisson regression analysis with log link function and log of total surface-years at risk as an offset term was used to assess statistical significance. A Poisson regression analysis was used to estimate the adjusted rate ratio and $95 \%$ CI directly comparing the treatment and control groups in terms of tooth decay progression. The model was adjusted for enrollment cohort, Head Start center, gender of child, child's age at baseline (quintiles), and child's caries status at baseline using 0 , $1-7$, and $>7 \mathrm{dmfs}$. Because there are often problems of overdispersion when using Poisson regression to model $\mathrm{dmfs}$ counts (variance larger in observed data than is assumed in model), we used 


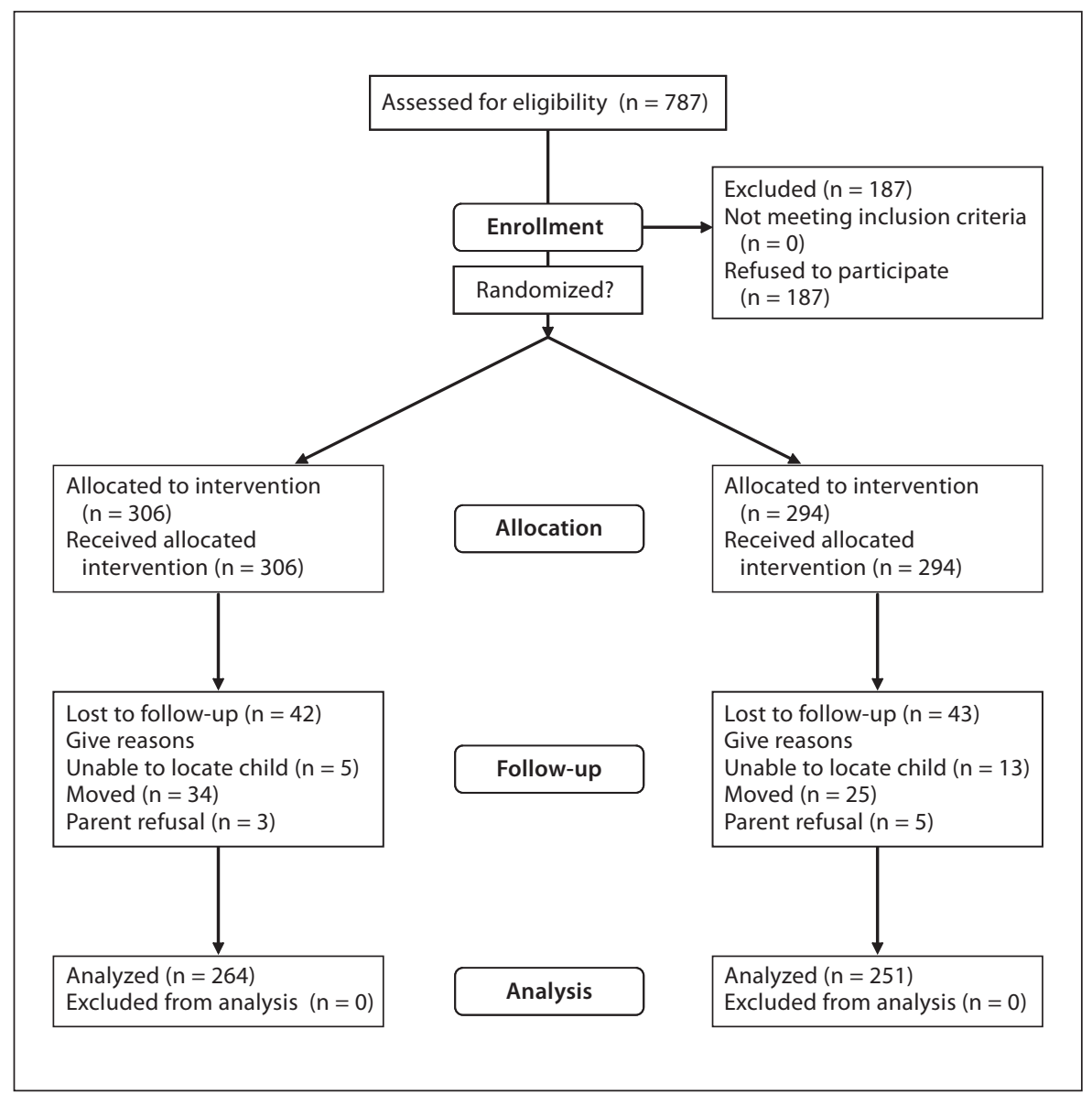

Fig. 1. Consort flowchart.

the robust variance estimator of generalized estimating equations in our models, which can account for the discrepancy [Hujoel et al., 1994]. The data were analyzed using $R$, version 2.7.1 [R Development Core Team, 2008].

\section{Results}

Enrollment was completed in February 2005. A total of 370 of $600(62 \%)$ children randomized were followed the entire 3 years, and 515 (86\%) attended at least one follow-up exam. The primary reason for loss to follow-up was inability of the study staff to locate the child/family (fig. 1). There were no adverse events in the study and no children were exited because of any problems with the varnish application.

Table 1 shows the baseline descriptive statistics by treatment group. Though the randomization was planned to be stratified by baseline $\mathrm{dmfs}$ ( $\leq 7 \mathrm{dmfs}$ and $>7 \mathrm{dmfs}$ ), errors by new, overworked staff resulted in an imbalance. The mean \pm SD dmfs observed at baseline in the stan- dard and intervention groups were $5.3 \pm 9.8$ and $7.2 \pm$ 9.3, respectively.

Table 2 presents the unadjusted mean numbers of surfaces with evidence of new decay observed in various groupings of the cohort. The unadjusted mean (SD) amount of new decay observed on primary surfaces in the intensive- and standard-treatment groups was 9.8 (8.6) and $7.4(7.7)$ surfaces, respectively $(\mathrm{p}=0.001)$. The rates of new decay observed in this cohort were 60 per 1,000 surfaces per year in the intensive group and 44 per 1,000 surfaces per year in the standard treatment group. Rates of new decay in primary surfaces were highly associated $(\mathrm{p}<0.001)$ with decay at baseline, and possibly related to enrollment cohort $(\mathrm{p}=0.06)$. For this age group the data for new decay in the permanent surfaces were quite sparse, but an association did appear evident with caries at baseline $(p=0.04)$. Rates of new decay in permanent teeth observed in the intensive and standard treatment groups were 14.8 and 11.4 DMFS per 1,000 surfaces per year, respectively. 
Table 1. Baseline descriptives for the equivalence trial subject population

\begin{tabular}{|c|c|c|}
\hline & \multicolumn{2}{|c|}{ Treatment group } \\
\hline & $\begin{array}{l}\text { standard } \\
(\mathrm{n}=306)\end{array}$ & $\begin{array}{l}\text { intensive } \\
(\mathrm{n}=294)\end{array}$ \\
\hline \multicolumn{3}{|c|}{ Enrollment cohort, n (\%) } \\
\hline First year & $74(24)$ & $78(27)$ \\
\hline Second year & $232(76)$ & $216(73)$ \\
\hline \multicolumn{3}{|c|}{ Head Start Center, n (\%) } \\
\hline WSMC & $259(84)$ & $244(83)$ \\
\hline EPIC & $47(16)$ & $50(17)$ \\
\hline \multicolumn{3}{|l|}{ Gender, n (\%) } \\
\hline Female & $148(48)$ & $150(51)$ \\
\hline Male & $158(52)$ & $144(49)$ \\
\hline \multicolumn{3}{|c|}{ Age at baseline, months } \\
\hline Mean $\pm \mathrm{SD}$ & $54.7 \pm 4.5$ & $55.8 \pm 4.7$ \\
\hline Range & $40-67$ & $43-71$ \\
\hline \multicolumn{3}{|c|}{ Baseline dmfs, n (\%) } \\
\hline $0 \mathrm{dmfs}$ & $159(52)$ & $96(33)$ \\
\hline $1-7 \mathrm{dmfs}$ & $81(26)$ & $100(34)$ \\
\hline$>7 \mathrm{dmfs}$ & $66(22)$ & $98(33)$ \\
\hline
\end{tabular}

Table 3 presents the results of a Poisson regression analysis. In this regression model, the rate of new caries in primary surfaces is the outcome variable. Treatment group is included as the variable of primary interest and enrollment cohort, Head Start center, gender of child, child's age at baseline, and child's caries status at baseline are included as adjustment variables.

The adjusted rate of newly decayed surfaces in primary teeth for those assigned to intensive treatment was $13 \%$ greater than for those assigned to standard treatment: rate ratio 1.13 (95\% CI $0.94-1.37$ ). This ratio of rates was not statistically significantly different from 1 $(\mathrm{p}=0.20)$. After adjustment, caries at baseline was still seen to be highly associated with later caries $(\mathrm{p}<0.001)$. An interaction between treatment group and baseline caries was tested and found to be not significant $(p=0.87)$. A similar analysis with the outcome being new tooth decay in the permanent surfaces produced a rate ratio of 1.19 (95\% CI $0.78-1.83, \mathrm{p}=0.42$, data not shown).

Table 2. Univariate results, unadjusted amount of newly decayed primary and permanent tooth surfaces $(\mathrm{n}=$ 515 children with at least one follow-up exam)

\begin{tabular}{|c|c|c|c|c|c|c|c|}
\hline & & \multicolumn{3}{|c|}{ Primary surfaces } & \multicolumn{3}{|c|}{ Permanent surfaces } \\
\hline & & $\begin{array}{l}\text { surface-years } \\
\text { at risk }\end{array}$ & $\begin{array}{l}\text { surfaces of new } \\
\text { decay per person }\end{array}$ & $\mathrm{p}$ & $\begin{array}{l}\text { surface-years } \\
\text { at risk }\end{array}$ & $\begin{array}{l}\text { surfaces of new } \\
\text { decay per person }\end{array}$ & $\mathrm{p}$ \\
\hline \multicolumn{8}{|l|}{ Treatment } \\
\hline Standard & 264 & $168 \pm 60$ & $7.4 \pm 7.7$ & \multirow[t]{2}{*}{0.001} & $38 \pm 30$ & $0.4 \pm 1.2$ & \multirow[t]{2}{*}{0.22} \\
\hline Intensive & 251 & $161 \pm 57$ & $9.8 \pm 8.6$ & & $40 \pm 27$ & $0.6 \pm 1.3$ & \\
\hline \multicolumn{8}{|c|}{ Enrollment cohort } \\
\hline First year & 132 & $160 \pm 56$ & $9.7 \pm 8.5$ & \multirow[t]{2}{*}{0.06} & $44 \pm 29$ & $0.7 \pm 1.6$ & \multirow[t]{2}{*}{0.12} \\
\hline Second year & 383 & $166 \pm 59$ & $8.2 \pm 8.1$ & & $38 \pm 28$ & $0.4 \pm 1.1$ & \\
\hline \multicolumn{8}{|c|}{ Head Start Center } \\
\hline WSMC & 434 & $167 \pm 59$ & $8.4 \pm 8.3$ & \multirow[t]{2}{*}{0.14} & $39 \pm 29$ & $0.5 \pm 1.2$ & \multirow[t]{2}{*}{0.05} \\
\hline EPIC & 81 & $155 \pm 52$ & $9.4 \pm 8.1$ & & $38 \pm 28$ & $0.8 \pm 1.5$ & \\
\hline \multicolumn{8}{|l|}{ Gender } \\
\hline Female & 249 & $164 \pm 58$ & $8.2 \pm 8.0$ & \multirow[t]{2}{*}{0.46} & $42 \pm 30$ & $0.5 \pm 1.3$ & \multirow[t]{2}{*}{0.67} \\
\hline Male & 266 & $165 \pm 59$ & $8.9 \pm 8.5$ & & $36 \pm 27$ & $0.5 \pm 1.2$ & \\
\hline \multicolumn{8}{|l|}{ Age quintile } \\
\hline 1 st & 104 & $175 \pm 67$ & $9.1 \pm 9.8$ & \multirow[t]{5}{*}{0.91} & $25 \pm 22$ & $0.3 \pm 0.9$ & \multirow[t]{5}{*}{0.70} \\
\hline 2nd & 102 & $166 \pm 60$ & $8.7 \pm 7.7$ & & $35 \pm 28$ & $0.5 \pm 1.2$ & \\
\hline $3 r d$ & 103 & $167 \pm 54$ & $8.6 \pm 8.3$ & & $38 \pm 26$ & $0.6 \pm 1.6$ & \\
\hline 4 th & 103 & $162 \pm 55$ & $7.8 \pm 7.4$ & & $44 \pm 29$ & $0.5 \pm 1.1$ & \\
\hline 5 th & 103 & $154 \pm 53$ & $8.6 \pm 8.0$ & & $55 \pm 30$ & $0.7 \pm 1.4$ & \\
\hline \multicolumn{8}{|l|}{ Baseline $\mathrm{dmfs}^{1}$} \\
\hline $0 \mathrm{dmfs}$ & 222 & $192 \pm 47$ & $5.7 \pm 7.1$ & \multirow[t]{3}{*}{$<0.001$} & $37 \pm 29$ & $0.4 \pm 0.9$ & \multirow[t]{3}{*}{0.04} \\
\hline $1-7 \mathrm{dmfs}$ & 152 & $170 \pm 50$ & $10.0 \pm 8.4$ & & $38 \pm 26$ & $0.5 \pm 1.2$ & \\
\hline$>7 \mathrm{dmfs}$ & 141 & $116 \pm 52$ & $11.6 \pm 8.3$ & & $44 \pm 31$ & $0.8 \pm 1.7$ & \\
\hline
\end{tabular}

${ }^{1} \mathrm{dmfs}$ in primary surfaces only. All children had zero DMFS in permanent surfaces at baseline. 
Table 3. Adjusted relative rates of new tooth decay in primary surfaces $(\mathrm{n}=515$ children with at least one follow-up exam)

\begin{tabular}{llll}
\hline Covariate & Rate ratio & $95 \%$ CI & p value \\
\hline $\begin{array}{l}\text { Treatment } \\
\quad \text { Standard }\end{array}$ & 1 & & 0.20 \\
$\quad$ Intensive & 1.13 & $0.94,1.37$ & \\
Enrollment cohort & & & 0.77 \\
$\quad$ First year & 1 & - & \\
$\quad$ Second year & 0.97 & $0.79,1.19$ & 0.68 \\
Head Start Center & & & \\
$\quad$ WSMC & 1 & - & 0.45 \\
$\quad$ EPIC & 1.05 & $0.83,1.34$ & \\
Gender & & & \\
$\quad$ Female & 1 & - & \\
$\quad$ Male & 1.07 & $0.89,1.29$ & \\
Age at baseline & & & \\
$\quad 40-50$ months & 1 & - & \\
$51-54$ months & 0.98 & $0.73,1.31$ & \\
$54-57$ months & 0.90 & $0.66,1.23$ & \\
$\quad 57-71$ months & 0.87 & $0.66,1.15$ & \\
Caries at baseline & & & \\
0 dmfs & 1 & - & \\
$1-7$ dmfs & 1.93 & $1.52,2.45$ & \\
$>7$ dmfs & 3.24 & $2.54,4.13$ & \\
\hline
\end{tabular}

\section{Discussion}

The children in this study experienced, on average, 8.6 new surfaces of tooth decay in their primary teeth and 0.5 new surfaces of tooth decay in their permanent teeth.

At about age 7, overall average dmfs and DMFS at the last examination were 10.0 and 0.5 , respectively. This compares to a national mean of $2.38 \pm$ (SE) $0.27 \mathrm{dfs}$ in children $2-5$ years old and $3.13 \pm 0.24$ for children aged 6-11 years [Beltrán-Aguilar et al., 2005] and $0.64 \pm 0.05$ DMFS in children aged 6-11 years. Both groups continued to experience new tooth decay. The mean decay increment in the primary teeth over the course of the study was $7.4 \mathrm{dfs}$ for the standard treatment and $9.8 \mathrm{dfs}$ for the intensive treatment. These findings raise further questions about the optimistic results of the largest US study [Weintraub et al., 2006], but are more consistent with the studies involving First Nation and American Indian children [Holve, 2008; Lawrence et al., 2008]. Differences may lie in the groups studied. The study by Weintraub et al. [2006] excluded children with caries at the start. The other studies, albeit with weaker designs, included children at very high risk.

The goal of our study was to establish whether the intensive treatment could be considered practically equiva- lent to the standard. It was decided a priori that equivalence would be established if the data were to rule out a difference of greater than $20 \%$ in rates of new caries. By this standard, the data in this study do not provide evidence of equivalence. New caries rates of up to $36 \%$ greater in the intensive group are included in the $95 \%$ CI for the rate ratio. On the other hand, the $\mathrm{CI}$ also includes the possibility of a $6 \%$ greater rate in the standard group; thus, the data also fail to provide conclusive evidence that the treatments differ. What does appear clear is that if the intensive treatment were superior, the advantage would be minimal. It seems apparent that in populations such as this one, in which $97 \%$ of children complete the school year, there is no practical advantage of the intensive treatment. In Head Start programs where families are migratory, and may be available only once per year, the application of three doses in the initial 2 weeks may provide protection from caries progression beyond the one application usually provided. However, no data are available that make the comparison between one application a year and the application of three doses within 2 weeks.

Recent data suggests that public health goals for preschoolers are not being met. The Healthy People 2010 Midcourse Review has found the USA moving away from the target it established for preschool children: a 57\% decrement was reported when 1988-1994 data were compared to 1999-2002 data [US DHHS, 2008]. The prevalence of tooth decay has increased and is especially severe for those living in poverty [Dye et al., 2007]. The lack of success of this study in finding a practical approach for fluoride varnish reapplication that fits with the needs of the low-income migratory population points to the need for studies of additional agents that could be used in conjunction with fluoride products. The use of topical povidone iodine seems promising [Lopez et al., 2002; Amin et al., 2004; Zhan et al., 2006].

\section{Acknowledgments}

Clinical Trials Registration: NCT00067353. This project was supported by Grants No. R01DE14403 and U54DE14254 from NIDCR, NIH. The active and placebo varnishes were provided by Omni Oral Pharmaceuticals. We would like to express our gratitude to Anita Partida, who directed and coordinated our efforts in the field, and her staff. We could have not been successful without their dedication to the study and the dental health of the children in the Yakima Valley. 


\section{References}

-Amin MS, Harrison RL, Benton TS, Roberts M, Weinstein P: Effects of povidone-iodine on Streptococcus mutans with extensive dental caries. Pediatr Dent 2004:26:5-10.

-Axelsson P, Paulander J, Nordvist K, Karlsson R: Effect of fluoride containing dentifrice, mouthrinsing, and varnish on approximal caries in a 3-year trial. Community Dent Oral Epidemiol 1987;15:177-180.

-Beltrán-Aguilar ED, Barker LK, Canto MT, Dye BA, Gooch BF, Griffin SO, et al, Centers for Disease Control and Prevention (CDC): Surveillance for dental caries, dental sealants, tooth retention, edentulism, and enamel fluorosis - United States, 1988-1994 and 19992002. MMWR Surveill Summ 2005;54:143.

Broadbent JM, Thomson WM: For debate: problems with the DMF index pertinent to dental caries data analysis. Community Dent Oral Epidemiol 2005;33:400-409.

-Drury TF, Horowitz AM, Ismail AI, Maertens MP, Rozier RG, Selwitz RH: Diagnosing and reporting early childhood caries for research purposes: a report of a workshop sponsored by the National Institute of Dental and Craniofacial Research, the Health Resources and Services Administration, and the Health Care Financing Administration. J Public Health Dent 1999;59:192-197.

Dye BA, Tan S, Smith V, Lewis BG, Barker LK, Thornton-Evans G, et al: Trends in oral health status: United States, 1988-1994 and 1999-2004. National Center for Health Statistics. Vital Health Stat 2007;11:1-92.

- Ensor T, Cooper S: Overcoming barriers to health service access: influencing the demand side. Health Policy Plan 2004;19:6979.
Grodzka K, Augustyniak L, Budny J, Czarnocka K, Janicha J, Mlosek K, Moszczenska B, Szpringer M, Wacinska M, Petersson L, Frostell G: Caries increment in primary teeth after application of Duraphat fluoride varnish. Community Dent Oral Epidemiol 1982;10: 55-59.

Holve S: An observational study of the association of fluoride varnish applied during well child visits and the prevention of early childhood caries in American Indian Children. Matern Child Health J 2008;12(suppl 1):6467.

Hujoel PP, Isokangas PJ, Tiekso J, Davis S, Lamont RJ, DeRouen TA, Mäkinen KK: A reanalysis of caries rates in a preventive trial using Poisson regression models. J Dent Res 1994;73:573-579.

Ismail AI, Brodeur JM, Gagnon P, Payette M, Picard D, Hamalian T, Olivier M, Eastwood BJ: Prevalence of non-cavitated and cavitated carious lesions in a random sample of 7-9. year-old schoolchildren in Montreal, Quebec. Community Dent Oral Epidemiol 1992; 20:250-255.

Lawrence HP, Binguis D, Douglas J, McKeown L, Switzer B, Figueiredo R, Laporte A: A 2-year community-randomized controlled trial of fluoride varnish to prevent early childhood caries in Aboriginal children. Community Dent Oral Epidemiol 2008;36: 503-516.

Lopez L, Berkowitz R, Spiekerman C, Weinstein P: Topical antimicrobial therapy in the prevention of early childhood caries: a followup report. Pediatr Dent 2002;24:204-206.

Milgrom P, Weinstein P, Huebner C, Graves J, Tut O: Empowering Head Start to improve access to good oral health for children from low income families. Matern Child Health J DOI: 10.1007/s10995-008-0316-6.

- Murray JJ, Winter GB, Hurst CP: Duraphat fluoride varnish: a 2-year clinical trial in 5-yearold children. Br Dent J 1977;143:11-17.
Petersson LG, Arthursson L, Ostberg C, Jönsson G, Gleerup A: Caries-inhibiting effects of different modes of Duraphat varnish reapplication: a 3-year radiographic study. Caries Res 1991;25:70-73.

R Development Core Team: R: A Language and Environment for Statistical Computing. Vienna, R Foundation for Statistical Computing, 2008. http://www.R-project.org.

Seppä L, Tolonen T: Caries preventive effect of fluoride varnish applications performed two or four times a year. Scand J Dent Res 1990; 98:102-105.

$>$ Sköld L, Sundquist B, Eriksson B, Edeland C: Four-year study of caries inhibition of intensive Duraphat application in 11-15-year-old children. Community Dent Oral Epidemiol 1994;22:8-12.

US DHHS: HP 2010 Midcourse Review, 2008. www.healthypeople.gov/Data/midcourse/ html/focusareas/FA21TOC.htm. Accessed October 15, 2009.

Weinstein P, Riedy CA, Kaakko T, Nakai Y, Milgrom P, Domoto P, Koday M, Leroux B: A 1-year study of fluoride varnish dosing in high caries risk preschoolers. Eur J Paediatr Dent 2001;2:91-96.

-Weintraub JA, Ramos-Gomez F, Jue B, Shain S, Hoover CI, Featherstone JD, Gansky SA: Fluoride varnish efficacy in preventing early childhood caries. J Dent Res 2006;85:172176.

World Health Organization: Oral Health Surveys - Basic Methods, ed 4. Geneva, WHO, 1997.

Zhan L, Featherstone JD, Gansky SA, Hoover CI, Fujino T, Berkowitz RJ, Den Besten PK: Antibacterial treatment needed for severe early childhood caries. J Public Health Dent 2006; 66:174-179. 